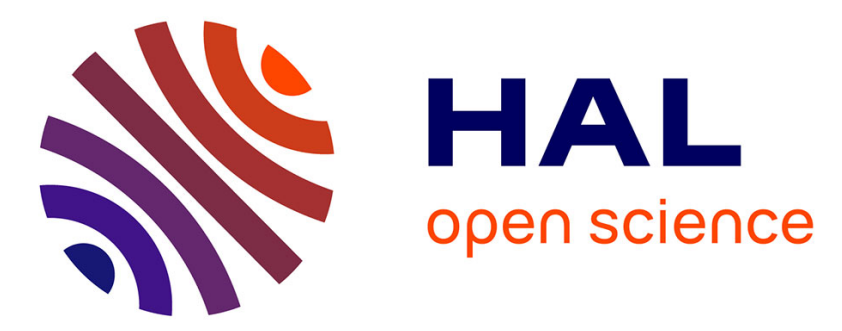

\title{
First evidence for large earthquakes on the Deshir Fault, Central Iran Plateau
}

\author{
H. Nazari, M. Fattahi, Bertrand Meyer, Michel Sébrier, M. Talebian, M. \\ Foroutan, Kristell Le Dortz, M.D. Bateman, M. Ghorashi
}

\section{- To cite this version:}

H. Nazari, M. Fattahi, Bertrand Meyer, Michel Sébrier, M. Talebian, et al.. First evidence for large earthquakes on the Deshir Fault, Central Iran Plateau. Terra Nova, 2009, 00, pp.1-10. 10.1111/j.13653121.2009.00892.x . hal-00425581

\section{HAL Id: hal-00425581 \\ https://hal.science/hal-00425581}

Submitted on 17 May 2013

HAL is a multi-disciplinary open access archive for the deposit and dissemination of scientific research documents, whether they are published or not. The documents may come from teaching and research institutions in France or abroad, or from public or private research centers.
L'archive ouverte pluridisciplinaire HAL, est destinée au dépôt et à la diffusion de documents scientifiques de niveau recherche, publiés ou non, émanant des établissements d'enseignement et de recherche français ou étrangers, des laboratoires publics ou privés. 


\section{列} 0

\section{First evidence for large earthquakes on the Deshir Fault, Central Iran Plateau}

Nazari H. ${ }^{1}$, Fattahi M. ${ }^{2,3,4}$, Meyer B. ${ }^{5}$, Sébrier M. ${ }^{5}$, Talebian M. ${ }^{1}$, Foroutan M. ${ }^{1}$, Le Dortz K. ${ }^{5}$, Bateman M. D. ${ }^{3}$, and M. Ghorashi ${ }^{1}$.

1: Institute for Earth Sciences, Geological Survey of Iran, Po Box:13185-1494,Teheran-Iran. email: nazari@gsi-iran.org, talebian@gsi-iran.org, foroutan@gsi.ir, ghorashi@gsi-iran.org 2: The Institute of Geophysics, University of Teheran, Teheran, Iran. email:mfattahi@ut.ac.ir 3: Sheffield Centre for International Drylands Research, Department of Geography, University of Sheffield, Winter Street, Sheffield S10 2TN, UK email: M.D.Bateman@Sheffield.ac.uk 4: Oxford University Center of Environment South Parks Road,Oxford, OX1 3QY,England email : morteza.fattahi@ouce.ox.ac.uk 5 : UPMC Univ Paris 06, ISTEP (UMR 7193 CNRS), F75005, Paris, France email: bertrand.meyer@upmc.fr, michel.sebrier@upmc.fr, kristell.le dortz@upmc.fr

short title: Large earthquakes on the Deshir Fault, Central Iran 1 


\section{Abstract}

Although sliced by several strike slip faults, a large part of Central Iran remained aseismic during the period of time covered by the instrumental and historical seismic records. Stating the existence of earthquakes in the Holocene is therefore important for the assessment of the regional seismic hazard. A paleoseismic study of the Deshir fault demonstrates that Central Iran hosted large earthquakes during latest Pleistocene and Holocene. The last event corresponds to 1m-deep fissures which sandy infilling yielded an optically stimulated luminescence (OSL) age of $2.8 \pm 1.4 \mathrm{ka}$. At least two previous events, outlined by older fissures and/or colluvial wedges, have been recorded over the last 10-30 ka. The magnitudes are difficult to assess because the actual slips per event are unknown. The size of the fissures and the significant vertical displacement associated to a colluvial wedge are nevertheless compatible with $\mathrm{M} \approx 7$ events along a primary strike-slip surface break.

\section{Introduction and geological setting}

The Deshir Fault is the westernmost prominent N-striking dextral strike-slip fault of a series that slice Central and Eastern Iran (e.g.; Berberian, 1981; Walker and Jackson, 2004; Meyer and Ledortz, 2007; inset, Figure 1). The fault locates North of the Zagros, nearby $54^{\circ} \mathrm{E}$, and cuts across an area of the Central Iran Plateau devoid of instrumental and historical seismicity (Ambraseys and Melville, 1982; Ambraseys and Jackson, 1998). Despite the lack of seismicity in its vicinity and the absence of resolvable deformation by the GPS network in Central Iran over two (Vernant et al., 2004) and six (Masson et al., 2007) years, the fault has long been suggested active (e.g., Berberian, 1981). There is now morphologic evidence for it and right-lateral offsets document a cumulative fault-slip of $\sim 25 \mathrm{~m}$ at several sites along the fault (Meyer et al., 2006). However, the Holocene time-period over which it surmised to have accumulated remains questionable. Although Meyer et al. (2006) suggested small stream offsets of 4-5m to the south of Marvast might result from coseismic slip during an earthquake of unknown age and magnitude $\sim 7$, the seismic behaviour of the Deshir fault is still not assessed. Trenching appears therefore appropriate to document Holocene earthquakes, if there were any, in a region that long remained quiescent according to the seismic records.

The information on the geometry and overall fault morphology is summarized from Meyer et al. (2006). The Deshir fault is a 380-km long straight strike-slip fault involving several portions (Figure 1). The northern portion, located between Nain and Deshir, disrupts the western part of the Nain-Baft suture and cuts across the Urumieh Doktar magmatic arc. 
The southern 230-km-long portion extends between Deshir and Harat, and cuts the eastern part of the Nain-Baft suture. The piercing points of the suture are difficult to pinpoint and estimates of the total dextral offset range between 50 and $80 \mathrm{~km}$. South of Deshir, the fault trends N150-160 and runs obliquely across coalescent fans that merge with Quaternary salt flat depressions. Within the salt flats, the fault intersects marshes along an ill-defined scarp. Through the coalescent fans, the fault bears a clear 2- to-20 $\mathrm{m}$ high cumulative scarp depending on the relative ages of the fans, and its prevalent dextral motion is attested by deflected river courses and offsets of terrace-risers. We scrutinized the southern fault portion on SPOT imagery and in the field, searching for the favourable places to conduct paleoseismic investigations and document the seismic history of the fault. We excavated trenches at three sites several tens of kilometres apart. Two revealed evidences of paleoseismic events. The third revealed unsuitable and showed distributed shear across steeply-dipping neogene units without convincing evidences of deformation of the thin discontinuous aeolian sands mantling the Neogene. We report here the observations gathered at the northernmost site where the lithology allowed us to unambiguously distinguish several events.

\section{The trench site and the excavation}

The excavation site is located North of Marvast where the fault cuts across a large intermittent stream that supplies water to the Deshir salt flat. Except for the main river flood plain where it has been eroded, the fault scarp is readily seen on the SPOT imagery and well expressed in the field (Figure 2). The scarp is less than $2 \mathrm{~m}$-high, faces to the east, and delineates a subtle depression or furrow associated to prevalent strike-slip motion. Tiny morphological features are well resolved on the right bank of the river where the fault cuts across an abandoned fan surface. Several ephemeral gullies denoted by grey linear areas have incised the fan surface to join the active flood plain. The gullies have probably formed as a result of regressive erosion since the last significant incision of the network. Close to the main river flood plain, one such gully, less than $200 \mathrm{~m}$ long, flows nearby and parallel to the fault. Further to the south, the fault intersects at right angle several gullies, a few tens to a few hundreds of meters long. The right-lateral offset of the two gullies to the south amounts to $25 \pm 5 \mathrm{~m}$. In between the smallest of the gullies intersecting the fault and the upper reaches of the gully paralleling it, there is a $30-50 \mathrm{~m}$ long section of the scarp preserved from recent erosion (Figures 2,3a). The smooth scarp delineates a subdued, 10-20m wide, $1.5 \mathrm{~m}$ deep, 
105 depression denoted by white patches on the SPOT image (Figure 3b). These white patches

106 outline the accumulation of a thin layer of silts and clays washed out from the scarp during episodic surface runoff. We discuss the most elucidating wall of a $25 \mathrm{~m}$ long, $2 \mathrm{~m}$ wide, $4 \mathrm{~m}$ deep trench excavated across this depression.

\section{Trench stratigraphy}

The trench wall (Figure 4) exhibits highly disrupted, coarse Quaternary deposits so that unit correlations across fault splays (f1 to f6) may be questionable. The overall structure of the trench corresponds to an asymmetric sag, limited to the east by the main fault zone (MFZ) and to the west by the f1 fault. The latter has controlled the development of the eastfacing scarp that delineates the Deshir fault along several tens kilometres on the satellite imagery (Figures 1,2). The eastern part of the trench is a tilted block, which extends between the MFZ and the easternmost faults (f5, f6). The overall structure thus suggests that the most recent deposits should have been trapped in the central part of the sag between $\mathrm{f} 1$ and $\mathrm{f} 2$. Despite the difficulties correlating units across individual faults, the overall stratigraphy is made of two main bodies of units: (1) older alluvial fanglomerates (blue colours, Figure 4) and (2) younger alluviums and colluviums (non-blue colours). The units have been described separately within the different blocks (Table 1 and Figure 4) and named accordingly with different letters (A to E) followed by a numbering order from bottom to top. Older units (A1, C1, D1, and E1) are exposed on both edges and in the lower part of the trench. They correspond to distal alluvial fan deposits that were probably shed by the Marvast River during Quaternary. Younger units of more local origin are exposed in the centre and the upper part of the trench and constst of:

(1) alluviums (A2, D2, D3, D4) corresponding to surface runoff sediments emplaced by short streams and small channels reworking older units and flowing mainly parallel to the fault. Such a network has probably been similar to the current second-order streams (Figure $2 a)$.

(3) colluviums corresponding to desert cover (A3, C2, 7), colluvial wedge (D5), or fissure fills (D6, part of unit 7). (OSL, Table 2). Although most ages have large uncertainties precluding accurate unit correlations, the ages indicate that unit 7 is Late Holocene (Marine Isotopic Stage MIS-1) 


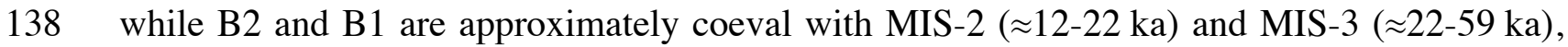
respectively. Then, D5, D6, and possibly C2 and A3 correlate with B2 (MIS2) whilst D4, D3,

140 Dx, and possibly A2 correlate with B1 (MIS-3). Aggradation of older alluvial units A1, C1,

141 D1 and E1 occurred partly during MIS-4 ( $\approx 59-80 \mathrm{ka})$. Finally, the calcrete formation should

142 be of Early-Middle Holocene age, as the youngest deposits (unit 7, 2.8 $\pm 1.4 \mathrm{ka}$ ) do not contain

143 calcretes.

\section{Seismic event identification}

The excavation evidences that coseismic surface ruptures have occurred repeatedly on the Deshir fault. The youngest event (ev1; Figures 4,5,6a) corresponds to open cracks and fissures filled by unit 7 and to the sealing unconformity on the Main Fault Zone. Indeed, a western MFZ splay, sealed by unit 7 whose thickness rapidly decreases eastward, indicates the occurrence of a small step prior to unit 7 , hence a surface break coeval with ev1. The largest fissures are recognized on the two walls of the trench; they strike N170-180 obliquely to the N160 fault zone and to the slope of the scarp, as expected for dextral en echelon tension gashes. These fissures are remnants of en echelon cracks along a primary dextral tectonic break. They postdate A3 and subsequent calcrete cementation and predate 7 not cemented by the calcrete. OSL dating within the infill of one of these fissures indicates that the causative seismic event occurred prior to $2.8 \pm 1.4 \mathrm{ka}$. Since the sandy-silty material that fills the fissure has a significant aeolian component, it was probably emplaced shortly after the earthquake during winter dust storm and the OSL age of the infill provides a likely estimate of the time of the earthquake. The event horizon, predating unit 7 , is distinguished all along the trench. In contrast, older events are difficult to correlate across the entire trench. They are described in each block and identified with the letters $\mathrm{T}$ to $\mathrm{Z}$ on Figure 4 .

In the central sag and West block, west of f2, two additional event horizons may be identified below the ev1 horizon: evZ predates B2 and postdates B1 since the base of B2 is filling a fissure along the upper termination of $\mathrm{f} 1$ (Figure 6b); evY predates A2 and postdates A1 as the base of A2 appears to be filling fissures within A1. Three OSL ages indicate that evZ should have occurred between 20.5 and $28.2 \mathrm{ka}$ and evY prior to $28.2 \mathrm{ka}$. Older seismic events may have occurred during B2 aggradation as this unit appears sealing $\mathrm{f} 2$ fault splays. However, their corresponding event horizons are not clearly identified within B2 unit. Four additional event horizons may be identified below ev1, between $\mathrm{f} 4$ and $\mathrm{f} 5$ in the Eastern 
171 D6 is cemented by the same calcrete to $\mathrm{D} 5$, evV cannot correspond to ev1, and therefore must 172 postdate the calcrete. If EvU predates the D5 colluvial wedge (Figure 6d) and postdates D4, 173 then evV and evU should correspond to surface breaks reactivating f5 between $2.8 \pm 1.4 \mathrm{ka}$ and $174 \quad 21.1 \pm 11.2 \mathrm{ka}$.

175 The two older events, evW and evT, are ill-defined. EvW may correspond to a small 176 crack splaying off fault f5 and sealed by D4 unit. If this is the case then it have occurred 177 between $21.1 \pm 11.2 \mathrm{ka}$ and $34.6 \pm 17.5 \mathrm{ka}$. EvT is extrapolated from the Western tilted zone 178 where the D2-D3 limit is an event horizon.

Three event horizons may be identified below ev1 in the Western tilted zone between

$180 \mathrm{f} 3$ and f4: evX predates C2 and postdates Dx. Indeed, the boundary between Dx and C2 appears as an event horizon as C2 is sealing f3 and most of the MFZ. Event evW would predate Dx and postdate D3, as the base of Dx appears filling a fissure along f4. EvT, predating D3 and postdating D2, corresponds to the sealing unconformity of a f3 fault splay with drag fold by D3 (Figure 6c). The OSL age of Dx indicates that evX postdates while evW and evT predate $41.5 \pm 15.9 \mathrm{ka}$. Only two events, ev1 and evX, can be identified in the MFZ. options may be contemplated for the penultimate event that occurred between 20.5 and 28.2 ka: (1) evV could correlate with evX and evZ, also seen as the penultimate event in their respective blocks or (2) evV is not present to the west of $\mathrm{f} 4$ fault and then, evU, evX, and evZ may correspond to the same event. Correlations for older events are only speculative: evW is ill-defined, inaccurately dated between 9.8 and $52.1 \mathrm{ka}$, and not recognized to the west of the MFZ; evT, which predates $34.6 \pm 17.5 \mathrm{ka}$ and $41.5 \pm 15.9 \mathrm{ka}$, might correlate with evY.

\section{Conclusions}

Paleoseismic data give evidence for a maximum of five earthquakes on the Deshir 196 fault during latest Pleistocene-Holocene. OSL dating constrains the late last three events to 197 the last $21.1 \pm 11.2 \mathrm{ka}$, suggesting a rough return period of $7 \pm 4 \mathrm{ka}$. The time elapsed since the last earthquake likely ranges between 1.4 to $4.2 \mathrm{ka} *^{1}$. The corresponding magnitudes, specifically for strike-slip earthquakes in a single trench, remain difficult to assess because the actual slip per event is not accessible. It is nonetheless possible to place loose constraints on the size of two earthquakes. For the antepenultimate event, evU, the thickness of the colluvial 201

\footnotetext{
${ }^{1}$ During the review process of this manuscript, a subsequent study of a small subset of the OSL data explored non-standard methods and unconventional statistical tests to narrow the error bars and has resulted in a refined likely age of $2.0 \pm 0.2 \mathrm{ka}$ for the last earthquake (Fattahi et al., 2009).
} 
202

203

204

205

206

207

208

209

210

211

212

213

214

215

216

217

218

219

220

221

222

223

224

225

226

227

228

229

230

231

232

233

234

235

wedge D5 indicates significant $(\approx 1 \mathrm{~m})$ vertical offset, hence large (several metres) horizontal displacement, along a primary strike-slip break and appears compatible with an event of magnitude $M>6.5$. For the last event, the deep fissures in the trench are much larger than the small fissures observed along the tiny surface break of the $2003 \mathrm{M}=6.5$ Bam earthquake (Jackson et al., 2006). They rather compare with the prominent open fissures mapped along the $150 \mathrm{~km}$-long portion of the North Anatolian Fault broken by the Mw=7.6 Izmit (Barka et al., 2002) and Mw=7.2 Dücze (Akyuz et al., 2002) earthquakes. Accordingly, the last event evidenced in the trench might have been of magnitude $M \geq 7$ and large enough to account for the small stream offsets of 4-5 m documented by Meyer et al. (2006) only 30 kilometres to the South of the trench. Moreover, the gullies incised within the fan surface postdate the whole set of alluvial and colluvial units and yield a minimum slip-rate on the order of 0.8-2.5 $\mathrm{mm} / \mathrm{yr}$, assuming their $25 \mathrm{~m}$ offset is at most $21.1 \pm 11.2 \mathrm{ka}$ (age of D4, youngest colluviums predating the abandonment of the fan surface and subsequently incised by streams flowing through the fault zone).

Although providing rough estimates on the recurrence and loose constraints on the magnitude of earthquakes, such studies are the only conceivable way for assessing seismic hazard in regions where the seismic cycle spans a period of time longer than that accessible to instrumental and historical seismic records, as is the case of Central Iran. Several other faults, that are now recognized as active (e.g., Meyer et al., 2007; Walker, 2008) but whose seismic behaviour remains unknown, require a better description of the current tectonics and an appropriate hazard assessment by trenching and application of chronological control.

\section{Acknowledgments.}

This study benefited from logistic and financial assistance from Geological Survey of Iran. UPMC-Paris6, INSU-CNRS, and CNES-SPOT Image (ISIS0403-622, ISIS0510-812) provided complementary funding. KL received a Ministry of Research and Education scholarship granted by the President of UPMC. We acknowledge constructive criticisms by F. Cinti, J-F. Ritz, R. Walker, and one anonymous reviewer. Editor and Associate Editor, C. Doglioni and H. Pedersen, provided helpful suggestions.

\section{References}

Akyüz, H.S., R. Hartleb, A. Barka, E. Altunel, G. Sunal, B. Meyer, R. Armijo and J.B. de Chabalier, (2002). Field observations and slip distribution of the November 12, 1999 Düzce earthquake (M=7.1), Bolu-Turkey, Bull. Seism. Soc. Am., special volume 92, 61-66. 
Ambraseys, N. and Melville, C. (1982). A history of Persian earthquakes. Cambridge University Press. Ambraseys, N.N. \& Jackson, J.A (1998). Faulting associated with historical and recent earthquakes in the Eastern Mediterranean region. Geophysical Journal International , 133, 390-406.

Barka, A., H.S . Akyüz, G. Sunal, Z. Cakir, A. Dikba, B. Yerli, R. Armijo, B. Meyer, J.B. de Chabalier, T. Rockwell, J.R. Dolan, R. Hartleb, T. Dawson, S. Christofferson, A. Tucker, T. Fumal, R. langridge, H. Stenner, W. Lettis, J. Bachhuber and W. Page (2002). The August 17, 199 Izmit earthquake, M=7.4, Eastern Marmara region, Turkey : study of surface rupture and slip distribution, Bull. Seism. Soc. Am., special volume 92, 43-60.

Bateman, M.D. and Catt, J.A. (1996). An absolute chronology for the raised beach and associated deposits at Sewerby, East Yorkshire, England. Journal of Quaternary Science, 11(5), 389-395.

Berberian, M. (1981). Active faulting and tectonics of Iran. In: Gupta, H. and Delany, F. (editors), Zagros-Hindu Kush-Himalaya Geodynamic Evolution, Geodynamic Series, Chapter 3, 33-69. American Geophysical Union.

Fattahi, M., Walker, R., Hollingsworth, J., Bahroudi, A., Talebian, M., Armitage, S. and Stokes, S. (2006) Holocene slip-rate on the Sabzevar thrust fault, NE Iran, determined using Opticallystimulated Luminescence (OSL). Earth and Planetary Science Letters, 245: 673-684.

Fattahi, M., Walker, R., Khatib, M.M., Dolati, A. and Bahroudi, J. (2007) Slip-rate estimates and past earthquakes on the Doruneh fault, eastern Iran. Geophysical Journal International, 168: 691-709.

Fattahi, M., Nazari, H., Bateman, M.D., Meyer, B., Sébrier, M., Talebian, M., Le Dortz, K., Foroutan, M., Ahmadi Givi, F., and M. Ghorashi (2009). Refining the OSL age of the last earthquake on the Dheshir fault, Central Iran, in press, Quaternary Geochronology.

Jackson J., Bouchon M., Fielding E., Funning G., Ghorashi M., Hatzfeld D., Nazari H., Parsons B., Priestley K., Talebian M., Tatar M., Walker R., and Wright T. (2006) Seismotectonic, rupture process, and earthquake-hazard aspects of the 2003 December 26 Bam, Iran, earthquake. Geophysical Journal International 166(3), 1270-1292

Masson, F., M. Anvari, Y. Djamour, A. Walpersdorf, F. Tavakoli, M. Daignières, H. Nankali, S. Van Gorp (2007) Large-scale velocity field and strain tensor in Iran inferred from GPS measurements: new insight for the present-day deformation pattern within NE Iran, Geophysical Journal International, 170 (1), 436-440. doi:10.1111/j.1365-246X.2007.03477.x

Meyer, B., F. Mouthereau, O. Lacombe and P. Agard (2006), Evidence of Quaternary activity along the Deshir fault: implication for the Tertiary tectonics of Central Iran, Geophysical Journal International., 164, 192-201.

Meyer, B., and K. Le Dortz (2007), Strike-slip kinematics in Central and Eastern Iran: Estimating fault slip-rates averaged over the Holocene, Tectonics, 26, TC5009, doi:10.1029/2006TC002073.

Murray, A.S. and Wintle, A.G., 2000. Luminescence dating of quartz using an improved single-aliquot regenerative-dose protocol. Radiation Measurements, 32(1): 57-73. 
Vernant, Ph., F. Nilforoushan, D. Hatzfeld, M.R. Abassi, C. Vigny, F. Masson, H. Nankali, J. Martinod, A. Ashtiani, R. Bayer, F. Tavakoli, and J. Chery (2004), Present-day crustal deformation and plate kinematics in the Middle East constrained by GPS measurements in Iran and Northern Oman, Geophys. J. Int., 157, 381-398.

Walker, R. and J. Jackson (2004), Active tectonics and late Cenozoic strain distribution in Central and Eastern Iran, Tectonics, 23, TC5010, doi:10.1029/2003TC001529.

Walker, R. (2008), A remote sensing study of active folding and faulting in southern Kerman province, S.E. Iran. Journal of Structural Geology, 28, 654-668.

Figure captions

Figure 1: Simplified sismotectonic map of the Deshir fault. 1973-2008 seismicity from NEIC (http://neic.usgs.gov/neis/epic/). Background image is from SRTM data (http/:edcsgs9.cr.usgs.gov/pub/data/srtm/) supplemented with Landsat images for unfilled areas (mostly lakes and salt flats). Red square for location of figure 2. Insert locates the area within the simplified seismotectonic map of Iran. Red arrows are GPS velocities with respect to stable Eurasia (Vernant et al., 2004; Masson et al., 2007).

Figure 2: The excavation site. (a) SPOT satellite extract highlighting fault trace on both sides of a main river flood plain which tributaries have incised an abandoned fan. Right-lateral offset of two small gullies (circled area) is $20-30 \mathrm{~m}$. Rectangle $3 \mathrm{a}$ and line $3 \mathrm{~b}$ respectively locate 3-D enlargement and section in figure 3. T indicates position and approximate extent of analyzed trench. Right panels show enlargements of raw (top) and interpreted (bottom) images of the offset gullies. (b) Field photograph of the N160 linear, east-facing, 2m-high scarp. View is taken to the south from the eastern tip of the trench. Cars parked by the base of the scarp for scale.

Figure 3: a, 3-D perspective view of the excavation site obtained from draping a HR Quickbird image on a Digital Elevation Model worked out from a differential GPS survey. b, Topographic profile (VE 14) across the fault zone with dots indicating the density of the GPS survey. A depression outlines the strike-slip fault and a gentle warping to the East possibly reflects blind thrusting and upper slip partitioning of a slightly transpressive motion at depth. Box is projection of the excavated area in Figure 4. 
306 Figure 4: Photo-mosaic of the southern wall of the trench (top), corresponding log with

307 position of dated samples (middle), and simplified stratigraphy with emplacement of seismic event horizons (bottom). Boxes on upper panels locate the detailed photographs of figure 6 .

309 Colour variation and mismatch in the mosaic result from assembling more than 350

310 photographs. Sedimentary units are indicated by different colours and labelled numerically

311 from bottom to top. See Table 1 for detailed description of the sedimentary units. Location

312 and stratigraphic position of OSL samples (circled dots) are indicated. OSL data are provided

313 in Table 2. Evidences of individual events (question mark where tenuous, see text for discussion) are labelled with letters. Dashed lines and question marks figure the correlation of events proposed across the five distinctive parts of the trench.

Figure 5: Field photograph showing the upper part of the trench and the east-facing scarp in the background. View to the south with $1.65 \mathrm{~m}$ tall geologist for scale. The smooth topography of the scarp contrasts markedly with the rugged set of fissures disrupting a calcrete and filled by recent sediments (aeolian sands and thin slope colluviums of unit 7, see also Figure 4 and Table 1).

Figure 6: Evidence for coseismic deformations. a, 1m-deep fissure disrupting a gypsiferous calcrete developed from colluviums A3. The sandy-silty material of the fissure was emplaced probably during dust winter storms, shortly after the earthquake. The hole, $50 \mathrm{~cm}$ below ground surface, locates the OSL sample HI/2006-II. (b), fissure (dark blue flags) filled by sands abutting on f1 fault. (c), Steep faults disrupting coarse alluviums. The middle fault, disrupting an alternation of conglomeratic and sandy-silty layers (D2 unit), is sealed by a colluvium (D3 unit). (d), colluvial wedge (CW, brown horizontal layers, D5 unit) unconformable on $15-20^{\circ} \mathrm{E}$ dipping alluvial units tilted against a $50^{\circ} \mathrm{W}$ dipping fault. A fissure filled by gravely material and coarse sands (f, D6 unit) disrupts the colluvial wedge. The fissure and the colluvial wedge have been both indurated by a calcrete pedogenesis and coated by a thin layer of sand and silt. 


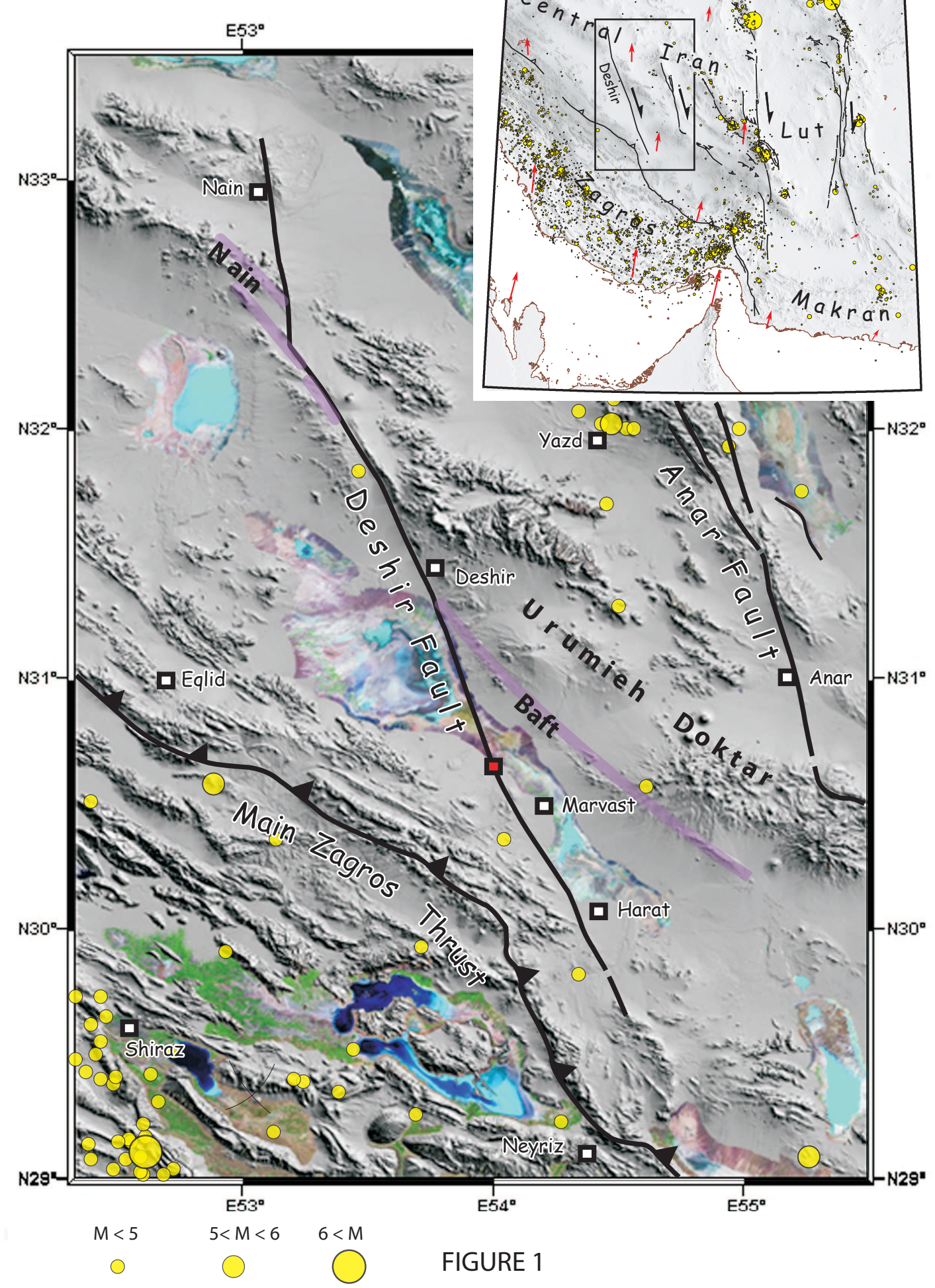




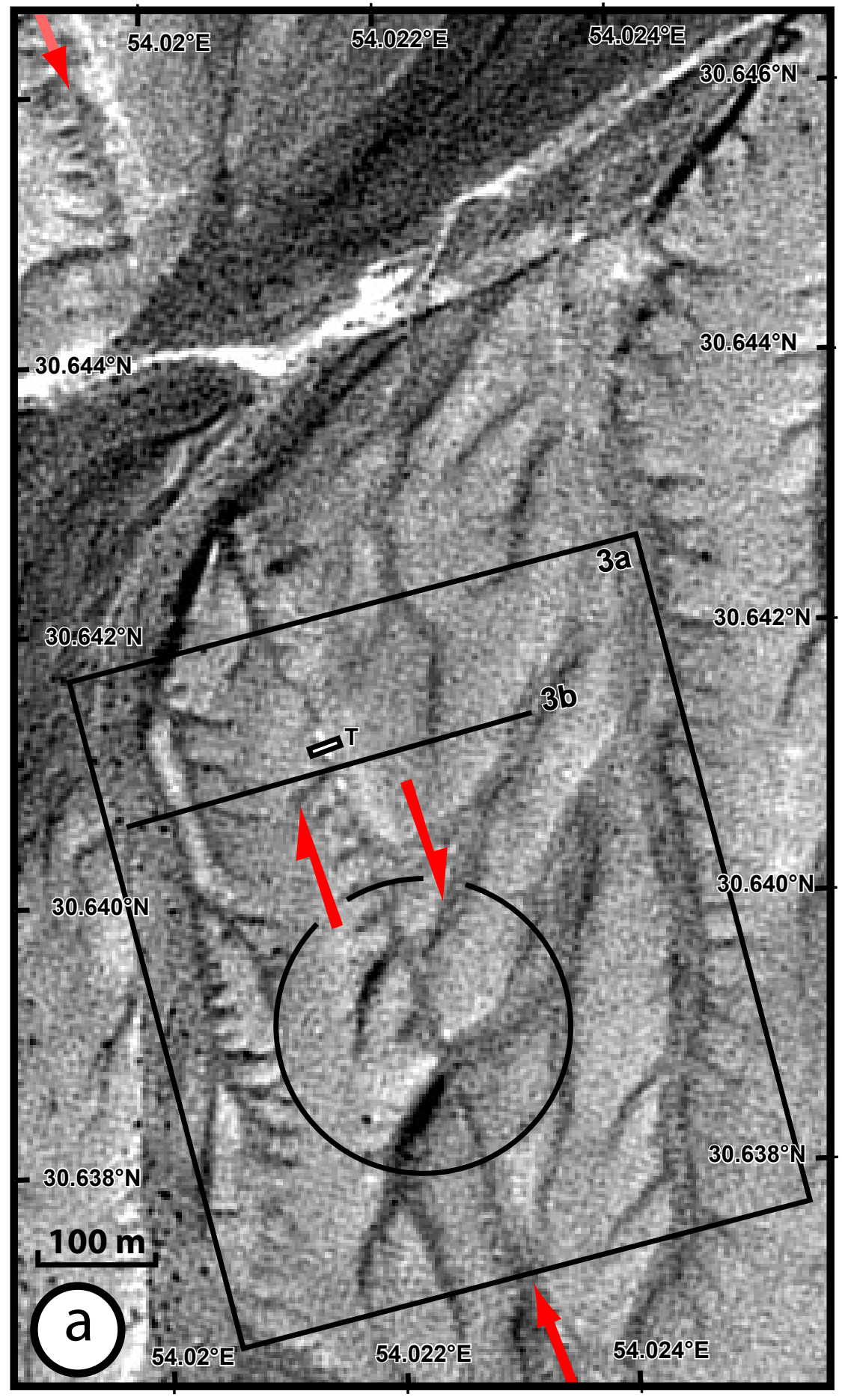

E
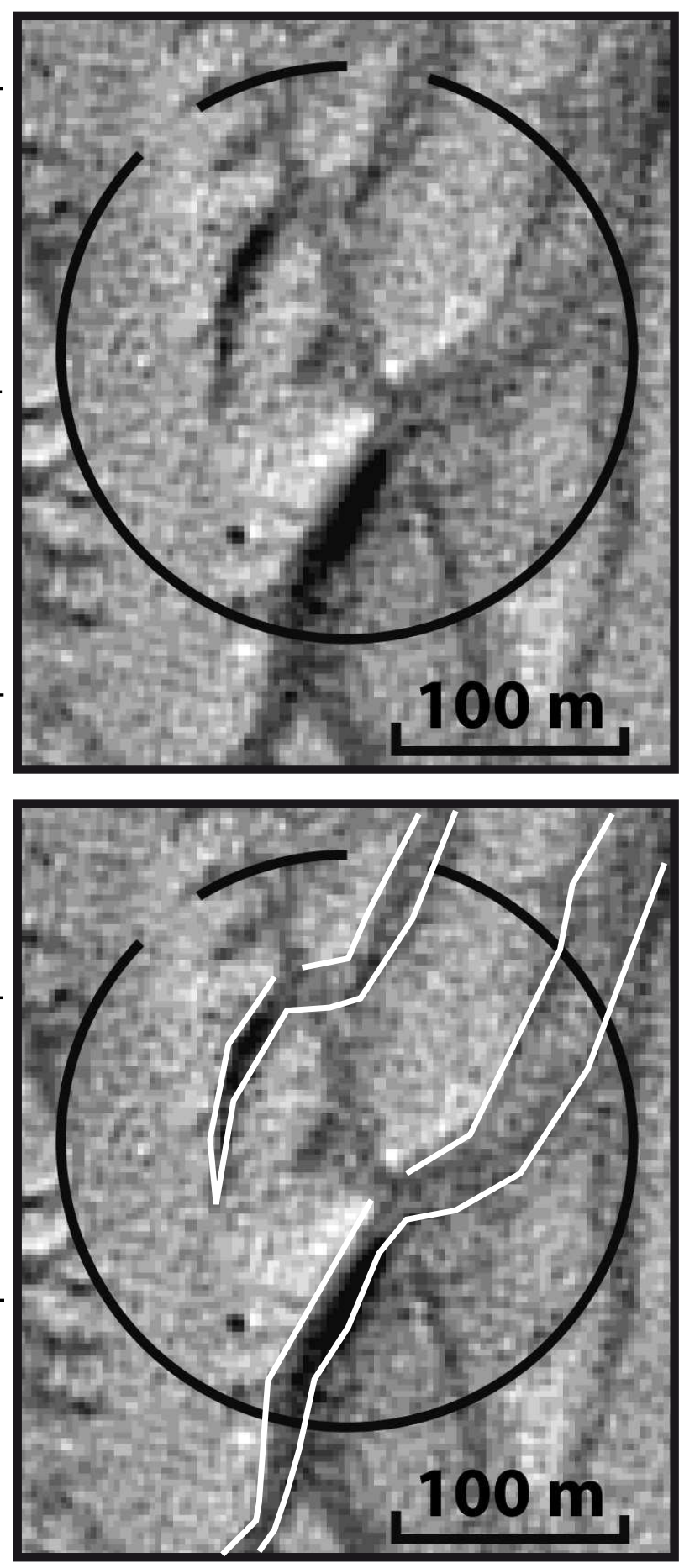

W

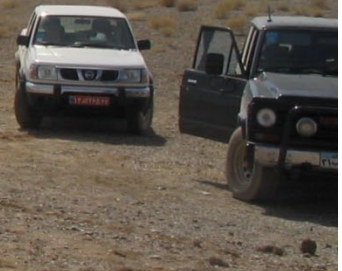

(b)

FIGURE 2 


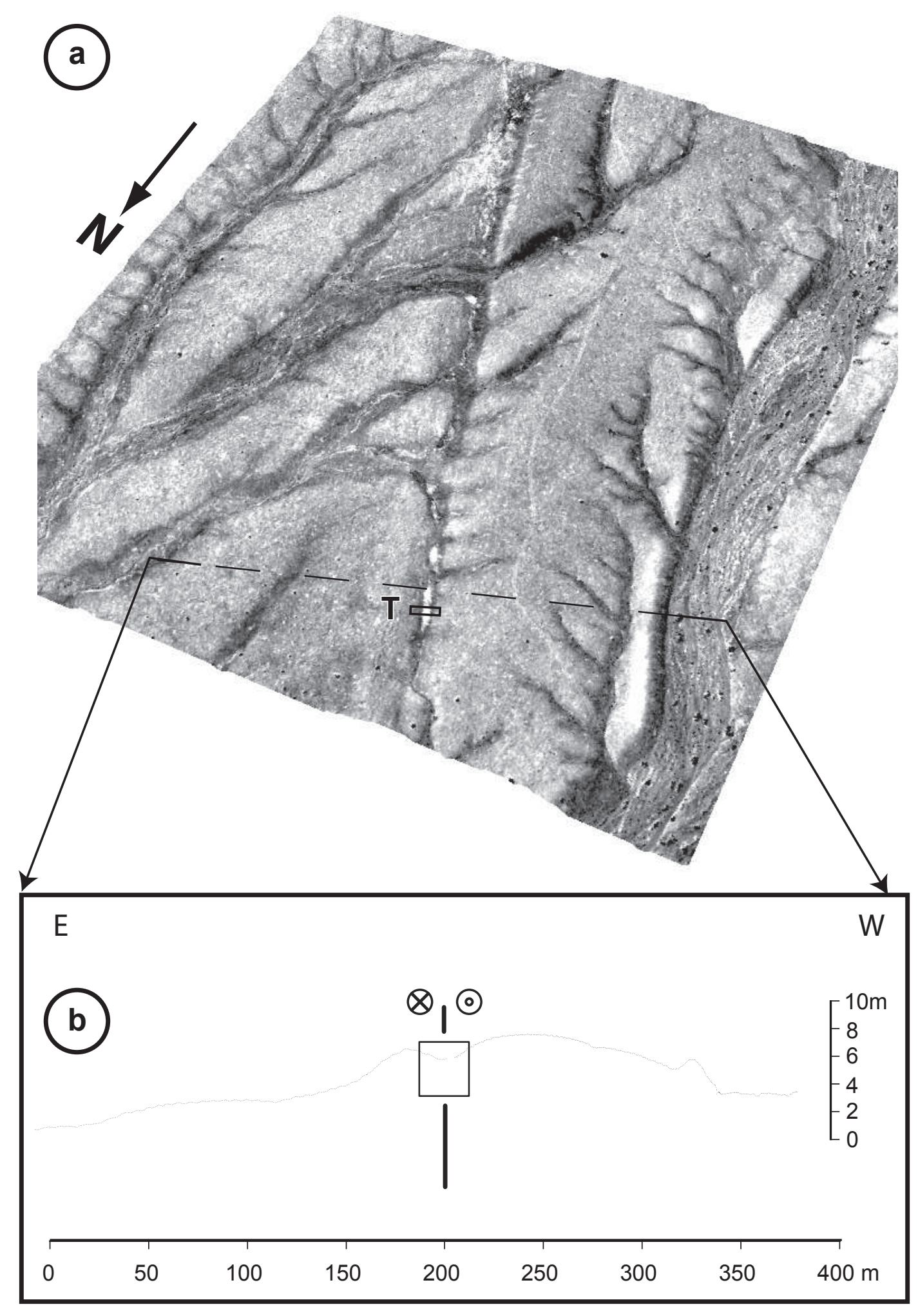

Figure 3 

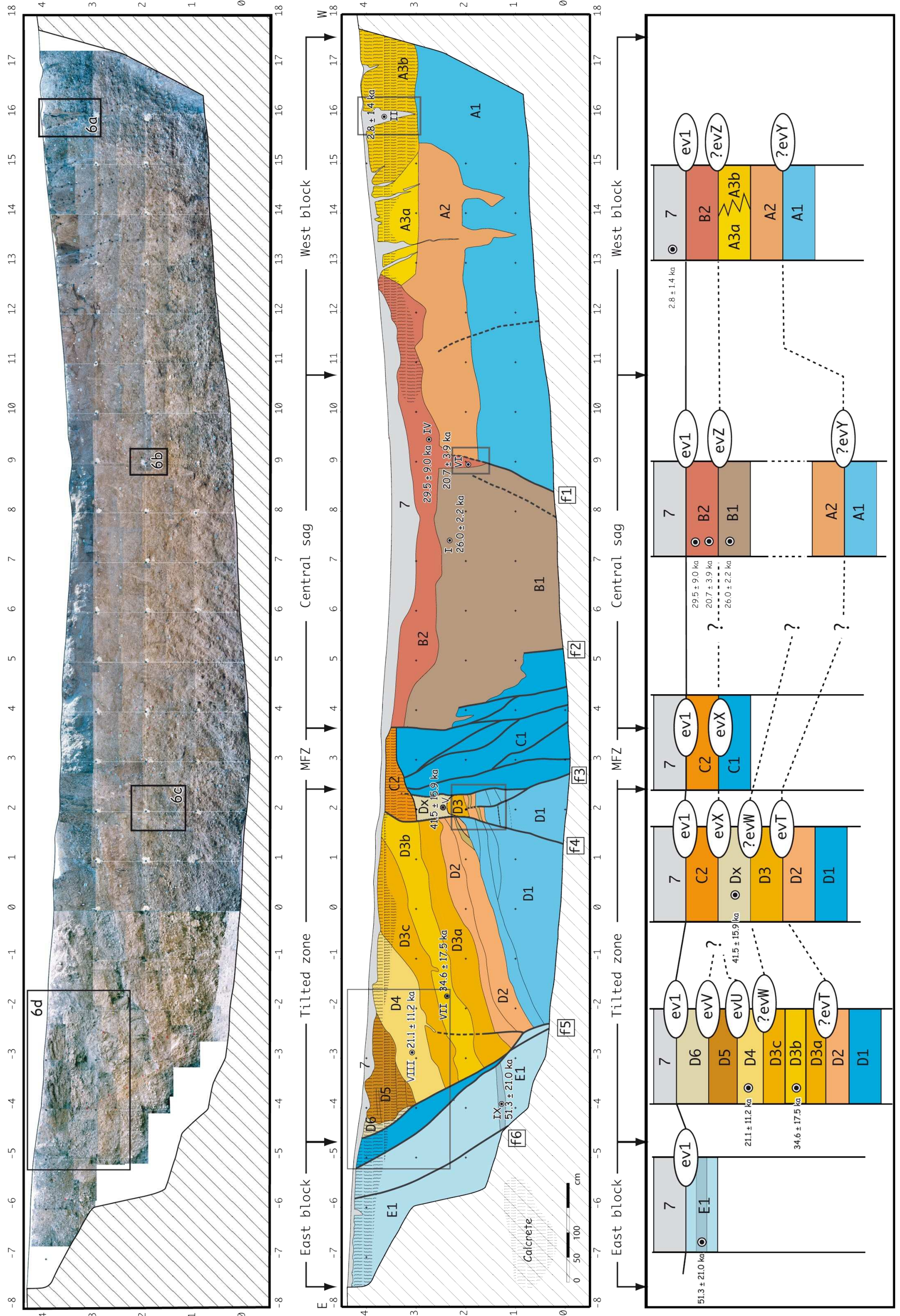


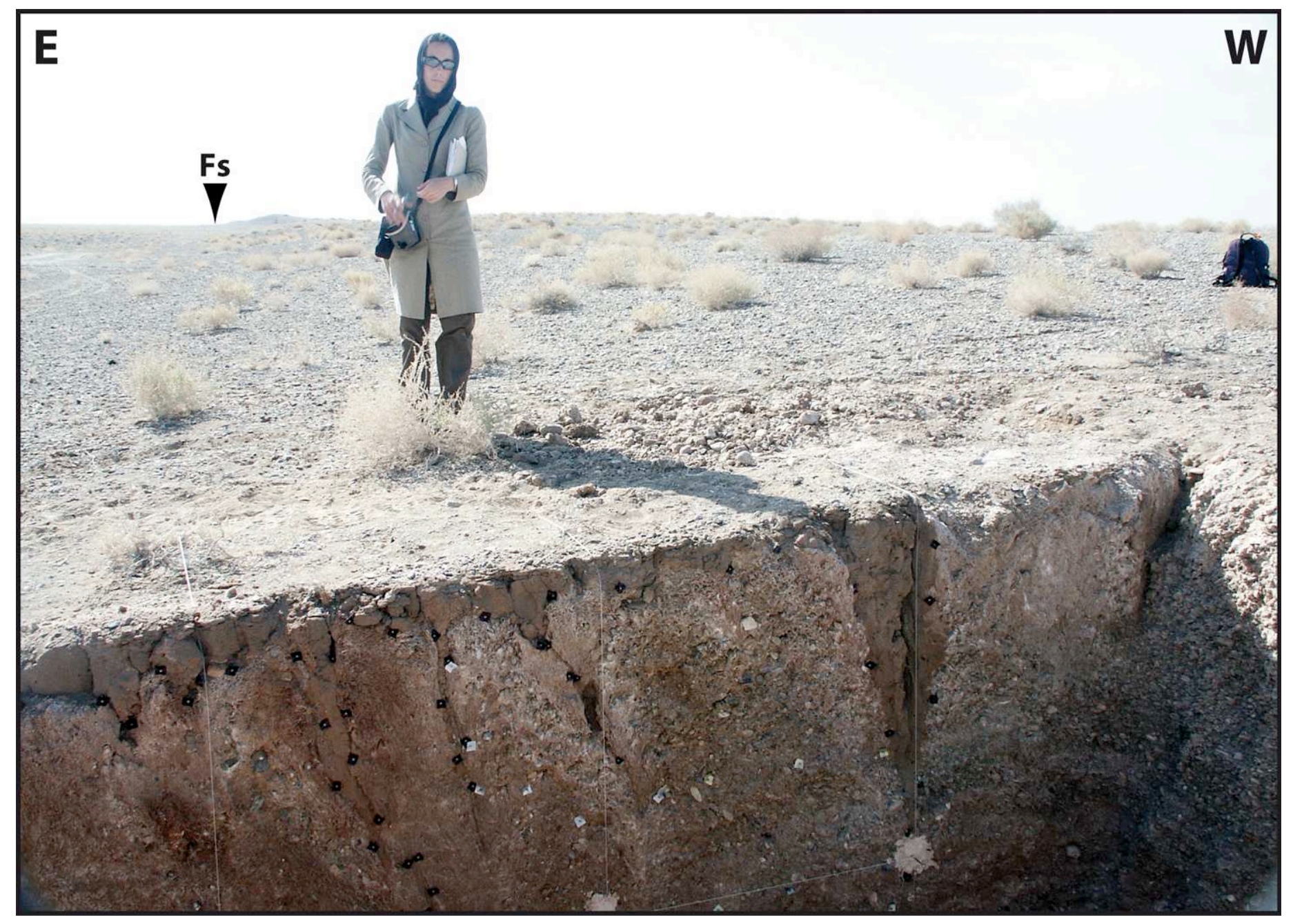



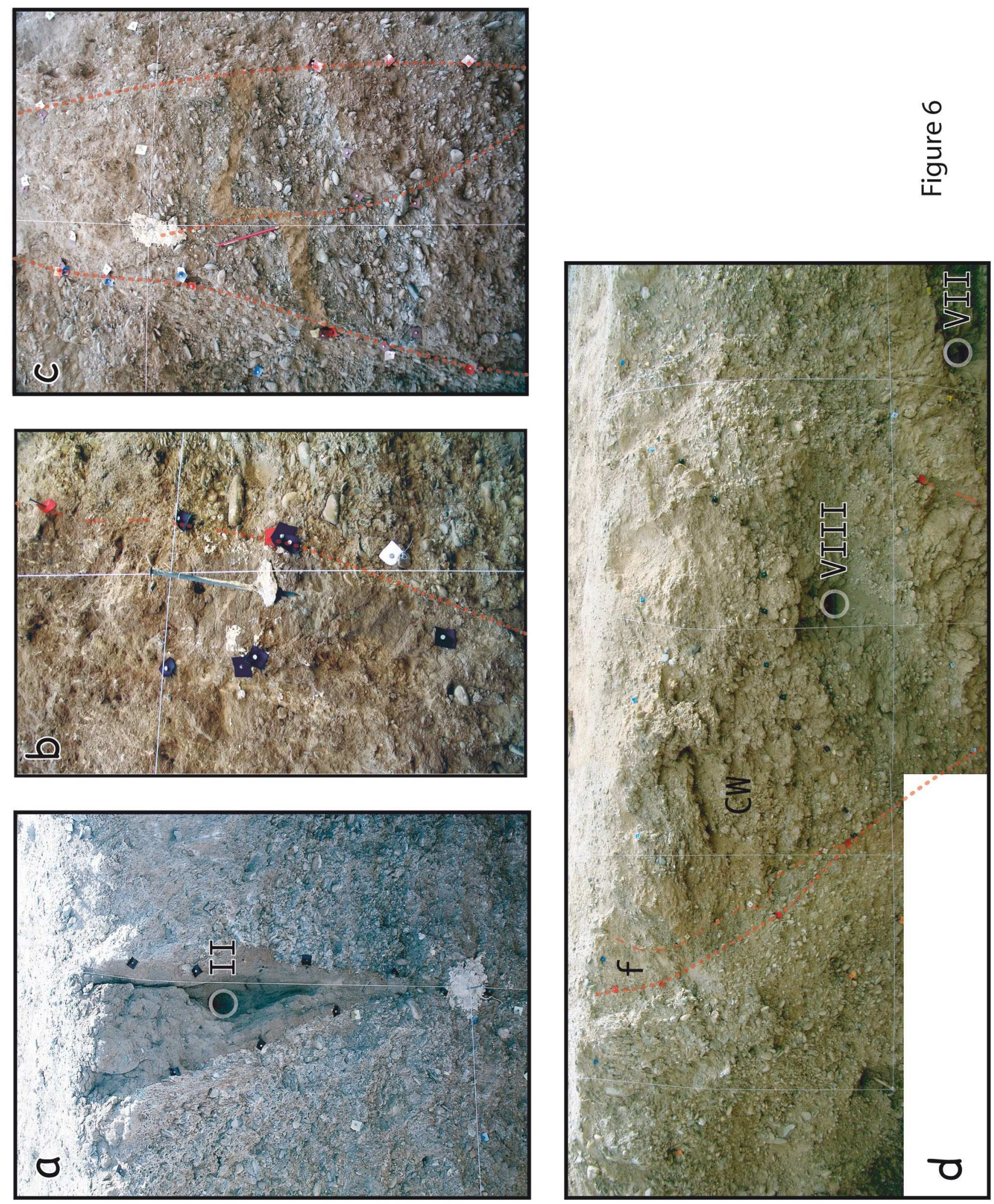


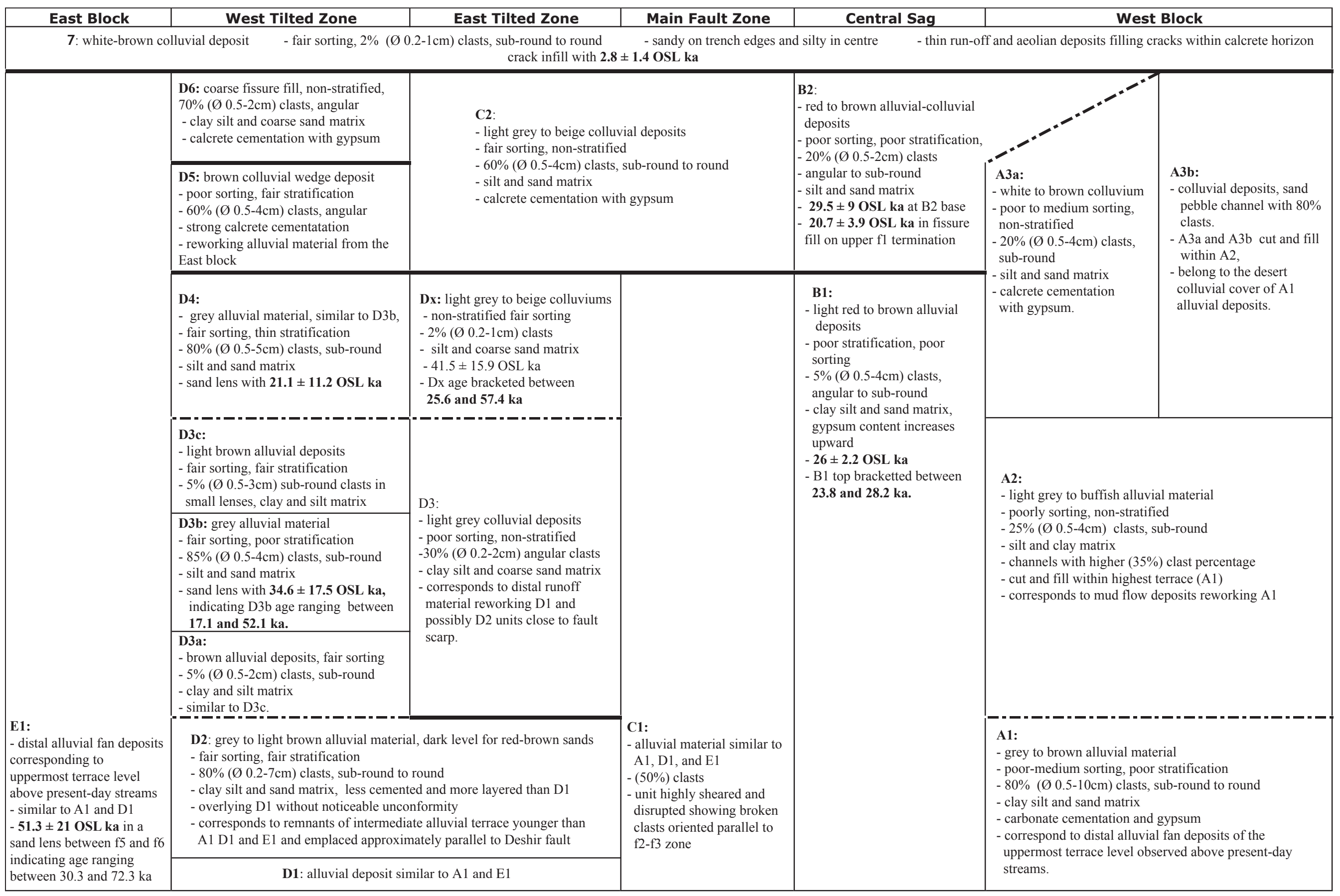


340 Table 1: Description of the sedimentary units observed within the Deshir trench (see Figure

341 4). Block names are in column headers and unit names are indicated in bold. Thin black lines

342 are either block limits (vertical) or boundary between units (horizontal). Thick continuous

343 black lines figure confidently determined event horizons of earthquake while thick dotted-

344 dashed lines represent questionable event horizon.

346 Table 2: Optically Stimulated Luminescence ages for the Deshir samples. Age determination 347 requires knowledge of the equivalent $\left(D_{e}\right)$ and annual $\left(D_{a}\right)$ doses for each sample. Ages have been calculated for Quartz grains with size ranging between 90 and 250 microns.

349

\begin{tabular}{|ll|c|c|c|c|c|c|c|c|}
\hline Sample $^{\mathrm{a}}$ & Unit & $\begin{array}{c}\text { Equivalent } \\
\text { Dose } \\
\text { De (Grays) }\end{array}$ & $\begin{array}{c}\text { depth } \\
(\mathrm{m})\end{array}$ & $\begin{array}{c}\text { Water } \\
(\%)\end{array}$ & $\begin{array}{c}\mathrm{K}^{\mathrm{c}} \\
(\%)\end{array}$ & $\begin{array}{c}\mathrm{U}^{\mathrm{c}} \\
(\mathrm{ppm})\end{array}$ & $\begin{array}{c}\text { Th}^{\mathrm{c}} \\
(\mathrm{ppm})\end{array}$ & $\begin{array}{c}\text { Annual Dose } \\
\text { rate } \\
\text { Da } \\
(\mathrm{Grays} / \mathrm{ka})^{\mathrm{d}}\end{array}$ & $\begin{array}{c}\text { Age } \\
(\mathrm{ka})^{\mathrm{e}}\end{array}$ \\
\hline $\mathrm{HI} / 2006-\mathrm{I}$ & $\mathrm{B} 1$ & $60.16 \pm 4.60$ & 1.2 & 0.9 & $1.22 \pm 0.01$ & $1.79 \pm 0.05$ & $6 \pm 0.1$ & $2.31 \pm 0.06$ & $26.0 \pm 2.2$ \\
\hline $\mathrm{HI} / 2006-\mathrm{II}$ & 7 & $5.00 \pm 2.37$ & 4 & 1.1 & $0.73 \pm 0.01$ & $1.67 \pm 0.05$ & $5.5 \pm 0.1$ & $1.76 \pm 0.04$ & $2.8 \pm 1.4$ \\
\hline $\mathrm{HI} / 2006-\mathrm{IV}$ & B2 & $70.21 \pm 21.24$ & 0.8 & 1.2 & $1.2 \pm 0.01$ & $2.09 \pm 0.05$ & $6 \pm 0.1$ & $2.38 \pm 0.06$ & $29.5 \pm 9.0$ \\
\hline $\mathrm{HI} / 2006-\mathrm{V}$ & Dx & $81.97 \pm 31.23$ & 1.3 & 1.0 & $0.98 \pm 0.01$ & $1.47 \pm 0.05$ & $5.9 \pm 0.1$ & $1.98 \pm 0.05$ & $41.5 \pm 15.9$ \\
\hline $\mathrm{HI} / 2006-\mathrm{VI}$ & B2 & $50.14 \pm 9.26$ & 1.5 & 1.3 & $1.27 \pm 0.01$ & $2.04 \pm 0.05$ & $6 \pm 0.1$ & $2.42 \pm 0.06$ & $20.7 \pm 3.9$ \\
\hline $\mathrm{HI} / 2008-\mathrm{VII}$ & D3b & $47.00 \pm 23.79$ & 1.6 & 1.1 & $0.61 \pm 0.01$ & $1.1 \pm 0.05$ & $4.3 \pm 0.1$ & $1.36 \pm 0.03$ & $34.6 \pm 17.5$ \\
\hline $\mathrm{HI} / 2008-\mathrm{VIII}$ & D4 & $30.64 \pm 23.77$ & 0.95 & 0.9 & $0.66 \pm 0.01$ & $1.13 \pm 0.05$ & $4.6 \pm 0.1$ & $1.45 \pm 0.03$ & $21.1 \pm 11.2$ \\
\hline $\mathrm{HI} / 2008-\mathrm{IX}$ & E1 & $71.63 \pm 29.22$ & 2.8 & 1.2 & $0.66 \pm 0.01$ & $1.12 \pm 0.05$ & $4.5 \pm 0.1$ & $1.40 \pm 0.03$ & $51.3 \pm 21.0$ \\
\hline
\end{tabular}

$351{ }^{a}$ The samples were collected using stainless steel tubes $(5 \mathrm{~cm}$ by $25 \mathrm{~cm})$ and both ends were sealed and covered using both aluminium foil and black tape. Quartz was extracted from all samples using standard methods in the Sheffield Centre for International Drylands Research Centre Luminescence Laboratory (see Bateman and Catt (1996) for details) $15)$ automated TL/OSL system. The equivalent dose $\left(D_{e}\right)$ was obtained using the conventional quartz single aliquot regeneration method (Murray and Wintle, 2000)

${ }^{\circ}$ Uranium, thorium and potassium concentrations were measured using inductively coupled

361

362 plasma mass spectrometer (ICP-MS) at SGS laboratories Ontario, Canada.

364

${ }^{\mathrm{d}}$ The annual dose $\left(D_{a}\right)$ was estimated from these data and the cosmic ray contributions as described in Fattahi et al. (2006 and 2007). 